\title{
Thermography-based approaches for multi-scale damage assessment in woven composite materials
}

\author{
by JM. Roche*, L. Muller, G. Celeste, A. Mavel, F. Passilly and F.-H. Leroy
}

* DMAS, ONERA, Université Paris-Saclay, Châtillon, France, jean-michel.roche@onera.fr

\begin{abstract}
The complexity of the non-destructive evaluation of the damage of woven composite materials, induced by mechanical loading, is mainly linked to its diversity, from microscale matrix cracking and local fibre/matrix debonding to mesoscale and macroscale intra-yarn cracking and delamination. The present paper aims at assessing the sensitivity of infrared thermography to such damage. Several experimental techniques are tested: once the limits of conventional active and passive thermography are identified, the relevance of lock-in thermography is highlighted. Optical microscopic observations as well as acoustic measurements are used to strengthen the conclusions of the thermal study.
\end{abstract}

\section{Introduction}

The morphology of damage induced in woven composite materials by mechanical loading has been thoroughly studied in the past few years [1]. Its complexity makes it particularly difficult to be detected by passive infrared (IR) thermography or by any other monitoring techniques (digital image correlation, acoustic emission). If the macroscale damage, such as intra-yarn cracking and delamination, can be spotted and located by IR thermography because of the heat it generates when it appears [2], it is much more complex when it comes to microscale matrix cracking. Some authors proposed an energy approach aiming at visualizing the portion of dissipated energy caused by damage [3]. As far as non-destructive inspection is concerned, conventional techniques such as active thermography or ultrasonic testing have shown their limits: even macroscale cracks become uneasy to detect once they are closed back up when the composite material is not under load anymore. Vibrothermography, which consists in detecting the local or global self-heating of the composite material due to the friction between the defect surfaces when they are put under vibration, seems to be a more promising approach [4]

The present study aims at assessing the sensitivity of various thermography-based approaches to multi-scale damage in woven composites. Three experimental techniques are considered: standard pulse thermography, used to inspect the material after the mechanical tests (Section 2); passive thermography, used to monitor the damage under mechanical loading (Section 2); lock-in thermography, used to visualize the harmonics of the thermal signal that might contain decisive data regarding the composite damage [5] (Section 3). In each case, advanced data processing methods are applied to improve the signal-to-noise ratio (SNR). The whole article is dedicated to the study of a $2.2 \mathrm{~mm}$ thick $2 \mathrm{D}$ woven carbon/epoxy composite material, constituted of three plies. Specimens of dimensions $250 \times 25 \mathrm{~mm}^{2}$ are tested. For all thermal acquisitions, a FLIR X6540sc mid-wave IR camera is used.

\section{Active and passive thermography for damage detection and monitoring}

Tensile tests are carried out on a $100 \mathrm{kN}$ mechanical machine. They are interrupted to levels from $20 \%$ to $90 \%$ of the failure stress value, to generate damage of increasing severity. As illustrated by Figure 1, pulse thermography, carried out using two flash lamps delivering a $6 \mathrm{~kJ}$ energy in $4 \mathrm{~ms}$ and recording the temperature decrease at a $50 \mathrm{~Hz}$ frequency during 30 seconds, is relevant for delamination detection but not for micro/mesoscale damage.

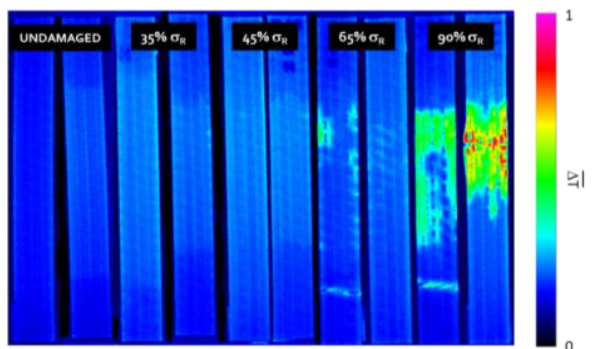

Fig. 1. Pulse thermography for damage inspection after mechanical testing. $200 \times 25 \mathrm{~mm}^{2}$ normalized temperature maps.

IR thermography can also be used in a passive mode to monitor the temperature variation of the front-face of the specimens under tensile loading. As expected, in accordance to the thermoelasticity theory, the temperature linearly decreases as long as the material remains in its elastic domain; then, the viscous effects start to slow down this 
decrease until damage appears and ultimately reverses the temperature evolution. In order to extract the actual thermal trend from the camera noise and any other convection disturbance, the raw thermal signal is filtered by a Gaussian filter and subsampled; it is then interpolated by the $\ell 1$ trend filtering, a statistical "segmented regression". It is finally possible to identify a stress threshold from which the temperature starts increasing. A margin of error is assessed after redistributing the noise by applying a circular permutation of the signal while maintaining its convex shape. This threshold, around $30 \%$ of the failure stress, matches with the appearance of the first microcracks in the woven composite, as it can be seen on the microscopic images of the polished free edge of the specimens, taken at the end of each test (Fig. 2). It also matches with the start of acoustic events, monitored by piezoelectric sensors during the tests.
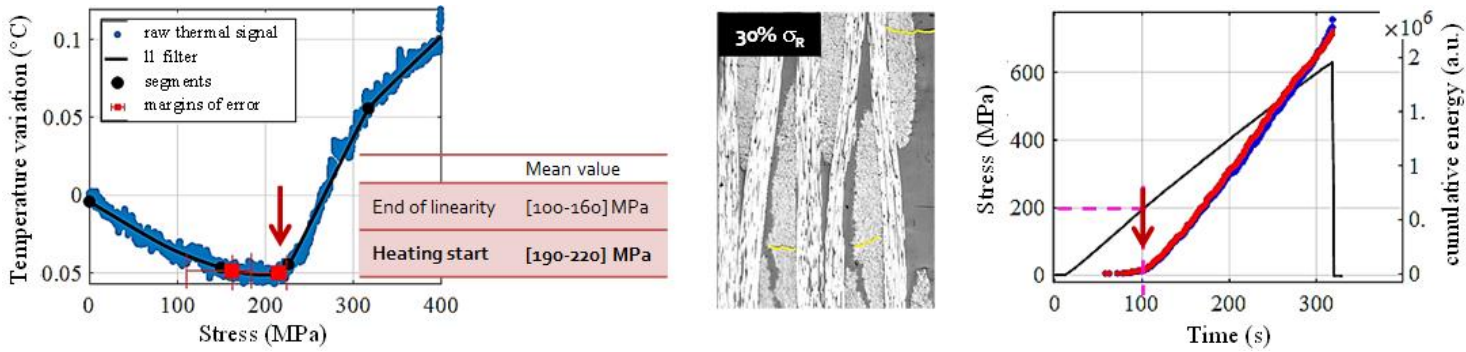

Fig. 2. Passive thermal monitoring of microscale matrix cracking under tensile loading. Temperature variation (left), microscopic image (middle), acoustic energy variation with the mechanical stress (right).

\section{Lock-in thermography for damage thresholds assessment}

Lock-in thermography is applied when the composite specimens are under cyclic loading, in two test configurations. In the first one, the load is induced by a $100 \mathrm{kN}$ hydraulic machine with a frequency of $5 \mathrm{~Hz}$ similar to the one used for fatigue tests. Its amplitude and average value increase from one step to another. In the second one, the load is induced by a $3 \mathrm{kN}$ "electropuls" machine with a frequency of $20 \mathrm{~Hz}$. Its amplitude is constant, fixed at a nondestructive value of $1.5 \mathrm{kN}$, and its average value is constant as well, fixed at $1.5 \mathrm{kN}$. Figure 3 gives a relevant illustration of how clearly the thermal harmonics are sensitive to the appearance of microscale damage in the woven composite: the amplitude of the first harmonic collapses while the amplitude of the second one starts emerging from noise. The identified thresholds match with the microscopic images and with the one assessed from passive thermography. Lock-in thermography seems to be even more reliable considering the unquestionable variations of the thermal harmonics.
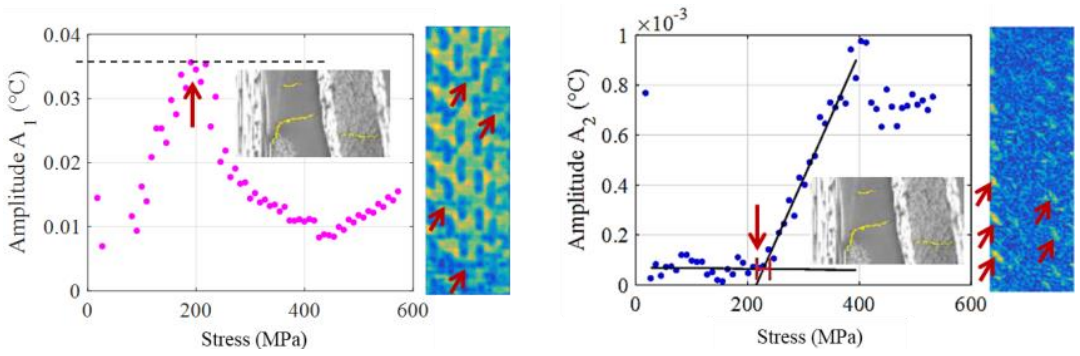

Fig. 3. Illustration of the sensitivity of the amplitudes of the first thermal harmonic (left) and the second thermal harmonic (right) to microscale damage induced in woven composites (see optical images).

\section{Conclusions}

The present study has enabled to assess the sensitivity of active, passive and lock-in thermography to multiscale mechanical damage of carbon/epoxy woven composites. A complete analysis will be provided in the final paper.

\section{REFERENCES}

[1] John S., Herszberg, F., Coman F., "Longitudinal and transverse damage taxonomy in woven composite components". Composites Part B: engineering, pp. 659-668, 2001.

[2] Roche JM., Lamboul B., Grail G., Osmont D., Balageas D., "Thermal and ultrasonics damage monitoring and characterization in woven composites", $19^{\text {th }}$ International Conference on Composite Materials, Montreal, 2013.

[3] Lisle T., Bouvet C., et al., "Damage of woven composite under tensile and shear stress using infrared thermography and micrographic cuts". Journal of Materials Science. Issue 18, Vol. 50, pp. 6154-6170, 2015.

[4] Bai G., Lamboul B., Roche JM., Baste S., "Investigation of multiple cracking in glass/epoxy 2D woven composites by vibrothermography". Quantitative InfraRed Thermography Journal, Vol. 13-1, pp. 35-49, 2016.

[5] Roche JM., Lamboul B., Bai G., Muller L., Paulmier P., Balageas D., "Lock-in thermography as a tool for fatigue damage monitoring of composite structures", $14^{\text {th }}$ Quantitative InfraRed Thermography Conf., Berlin, 2018. 